\title{
Lifestyle Intervention for Weight Loss: a group- based program for Emiratis in Ajman, United Arab Emirates
}

This article was published in the following Dove Press journal:

Diabetes, Metabolic Syndrome and Obesity:Targets and Therapy 18 March 2016

Number of times this article has been viewed

\author{
Amena Sadiya ${ }^{1, *}$ \\ Sarah Abdi ${ }^{\prime}, *$ \\ Salah Abusnana ${ }^{2}$ \\ 'Lifestyle Clinic, ${ }^{2}$ Research and \\ Education Department, Rashid Center \\ for Diabetes and Research, Ajman, \\ United Arab Emirates
}

*These authors contributed equally to this work

Correspondence: Amena Sadiya Lifestyle Clinic, Rashid Center for Diabetes and Research, PO Box 21499, Ajman, United Arab Emirates Tel +97I 503539532

Fax +97। 67434547

Email amena.sadiya@rcdr.ae
Background: Lifestyle Intervention for Weight Loss (LIFE-8) is developed as a structured, group-based weight management program for Emiratis with obesity and type 2 diabetes. It is a 3 -month program followed by a 1 -year follow-up. The results from the first 2 years are presented here to indicate the possibility of its further adaptation and implementation in this region.

Methodology: We recruited 45 participants with obesity and/or type 2 diabetes based on inclusion/exclusion criteria. The LIFE-8 program was executed by incorporating dietary modification, physical activity, and behavioral therapy, aiming to achieve up to $5 \%$ weight loss . The outcomes included body weight, fat mass, waist circumference, blood pressure, fasting blood glucose (FBG), hemoglobin A1c (HbA1c), and nutritional knowledge at 3 months and 12 months.

Results: We observed a reduction of $5.0 \%$ in body weight $(4.8 \pm 2.8 \mathrm{~kg}$; $95 \%$ CI $3.7-5.8)$, fat mass $(-7.8 \%, P<0.01)$, and waist circumference $(\Delta=4 \pm 4 \mathrm{~cm}, P<0.01)$ in the completed participants $(\mathrm{n}=28)$. An improvement $(P<0.05)$ in HbA1c $(7.1 \% \pm 1.0 \%$ vs $6.6 \% \pm 0.7 \%)$ and FBG $(8.2 \pm 2.0 \mathrm{mmol} / \mathrm{L}$ vs $6.8 \pm 0.8 \mathrm{mmol} / \mathrm{L})$ was observed in participants with obesity and type 2 diabetes after the program. Increase in nutritional knowledge $(<0.01)$ and overall evaluation of the program (9/10) was favorable. On 1-year follow-up, we found that the participants could sustain weight loss $(-4.0 \%)$, while obese, type 2 diabetic participants sustained HbA1c $(6.6 \% \pm 0.7 \%$ vs $6.4 \% \pm 0.7 \%)$ and further improved $(P<0.05)$ the level of FBG $(6.8 \pm 0.8 \mathrm{mmol} / \mathrm{L}$ vs $6.7 \pm 0.4 \mathrm{mmol} / \mathrm{L})$.

Conclusion: LIFE-8 could be an effective, affordable, acceptable, and adaptable lifestyle intervention program for the prevention and management of diabetes in Emiratis. It was successful not only in delivering a modest weight loss but also in improving glycemic control in diabetic participants.

Keywords: obesity, type 2 diabetes, UAE

\section{Introduction}

Obesity is an important public health problem around the world, and in the United Arab Emirates (UAE) approximately one in every three adults is obese. ${ }^{1}$ Rapid urbanization leading to lifestyle factors such as overconsumption of calories and decreased physical activity offers a reasonable explanation for this. ${ }^{2}$ More than $80 \%$ individuals with type 2 diabetes (T2D) are obese, indicating a strong correlation between obesity and T2D. ${ }^{3}$ Obesity not only impedes the management of T2D by increasing insulin resistance and blood glucose concentration but is also reported to be an independent risk factor associated with dyslipidemia, hypertension, and cardiovascular disease..$^{4,5}$ A moderate weight loss of $5 \%$ body weight is associated with the prevention of T2D progression in 
at-risk patients. ${ }^{6}$ It is also reported to improve insulin action and decrease the fasting blood glucose (FBG) concentrations in patients with T2D. ${ }^{7}$

Evidence-based guidelines for the management of obesity suggest a multidisciplinary approach, including a combination of diet, physical activity, and behavioral therapy. ${ }^{8}$ The effectiveness of low-fat, low-energy diets in combination with activity and lifestyle counseling has been demonstrated to result in 5\%-10\% weight loss and the reduction or prevention of comorbidities such as diabetes and/or hypertension. ${ }^{9}$ Recent guidelines also recommend group-based interventions in weight management, as they are cost efficient and show increased effectiveness in specific behavior-change strategies. $^{10}$

Landmark studies such as the Diabetes Prevention Program and Look AHEAD have presented a strong role of lifestyle intervention in the prevention and management of T2D. ${ }^{7,11}$ One of the most challenging aspects is the implementation of these positive results from clinical trials into usual care due to deficiency of resources and expertise in the area of lifestyle management in this region. Translation of these programs in Arabia is scarce. Ali et al explored the barriers to weight management for Emirati women and suggested the need for culturally acceptable, community-based interventions for the prevention and management of obesity among UAE women. ${ }^{12}$ A review of the demographic, social welfare, and behavioral variables and overweight prevalence in Arab countries has suggested that Arab women comprise a particularly vulnerable subgroup and the governments should act within religious and cultural parameters to provide environments that are conducive to a negative energy balance. ${ }^{13}$

We, at the Rashid Centre for Diabetes and Research, aimed at developing a well-conceived, professionally implemented, multidisciplinary, and group-based partial meal replacement/weight management program called Lifestyle Intervention for Weight Loss (LIFE-8). This ongoing program's overview and results for the first 2 years (October 2012 to December 2014) are presented here to indicate the possibility of its further adaptation and implementation to this region.

\section{Methodology Program overview}

The LIFE-8 program was developed by the Lifestyle Clinic at Rashid Centre for Diabetes and Research, a tertiary care center of diabetes and obesity in Ajman, UAE. Since this paper describes the structure and preliminary results of an evidence based clinical care program, ethical approval was not sought.
LIFE-8 was designed to deliver weight loss through lifestyle modification combining diet therapy, physical activity, and behavioral modification. The multidisciplinary team included dietitians, an exercise therapist, a nurse coordinator, and a physician. This weight management program approach has evolved from previous lifestyle programs reported from similar conditions. The goals of this program were adapted on the basis of the available evidence, recommendation, and clinical experience of local dietary patterns of Emiratis.

Our main objective was to assess the weight change after LIFE-8 program; however, the secondary objectives were to assess the changes in fat mass, FBG, hemoglobin A1c (HbA1c), and the knowledge score.

LIFE-8 program was designed to introduce and emphasize the following goals:

1. Limit cereal intake to 5-7 servings/d.

2. Increase vegetable intake to 3-4 servings/d.

3. Achieve physical activity of 7,000 steps/d-10,000 steps/d.

4. Encourage self-management skills for weight management.

Furthermore, the goals were individualized according to the need of the participant by a registered dietitian. This program was conveyed in eight sessions, ie, five groups and three individual sessions (Table 1). Individual sessions were utilized for the initial assessment, individualization of goals,

Table I Contents of each session in the Lifestyle Intervention for Weight Loss (LIFE-8)

\begin{tabular}{ll}
\hline Session & Topic \\
\hline Session I (group) & Introduction to program \\
& Readiness assessment \\
& Program expectation \\
Session 2 (individual) & Patient consent \\
& Nutritional assessment \\
& SMART goal setting \\
Introduce pedometers and diet diaries & (self-monitoring) \\
& Diet planning \\
& Food groups \\
Session 3 (group) & Ideal plate \\
& Menu planning \\
& Portion control \\
Session 4 (group) & Healthy cooking methods \\
& Improvising traditional recipes \\
Session 5 (individual) & Practical cooking session \\
Session 6 (group) & Diet and physical activity review \\
& Support and reward \\
Session 7 (individual) & Problem-solving skills \\
Session 8 (group) & Physical activity \\
& Development of healthy recipe \\
& Nutritional assessment \\
& Review of all sessions \\
& Weight maintenance \\
\hline
\end{tabular}

Abbreviation: SMART, specific, measurable, achievable, relevant, and time-bound. 
and follow-up. Group sessions were utilized for education and participatory cooking. This program strongly emphasized empowering the participants to make the right choices and adapting to behavioral changes. A structured approach was used for the session execution; core topics were discussed with the help of a standardized presentation. Each session lasted between 60 minutes and 120 minutes with six to ten participants.

\section{Participants}

Our program was conducted in the Lifestyle Clinic, an outpatient setting attached to an educational kitchen. Participants were registered through internal referrals and from other health care facilities in the Northern Emirates. The registrants were screened based on the following inclusionexclusion criteria: men and women of UAE nationality, age between 18 years and 50 years, obese (body mass index $[\mathrm{BMI}] \geq 30 \mathrm{~kg} / \mathrm{m}^{2}$ ) or obesity and with T2D (duration of diagnosis $\leq 5$ years), and committed for a 3-month program.
Participants were excluded if they had been diagnosed with T2D-associated complications or type 1 diabetes as well as pregnant or lactating women. Although 196 participants registered for this program, only 45 were recruited based on inclusion-exclusion criteria and their readiness to be assessed (Figure 1). Potential participants attended a group information meeting where the program details were discussed and readiness was assessed by a readiness assessment questionnaire adapted from the American Medical Association (2003), ${ }^{14}$ which recorded the reason to lose weight, family support interest, and readiness for a lifestyle change.

Eligible participants gave written consent of their participation in the program, and an initial nutritional assessment (60 minutes) was done to assess their FBG, HbA1c, blood pressure, body composition, waist circumference, usual dietary intake, and physical activity habits. The program was offered as a part of clinical care program, and there was no cost to the participant.

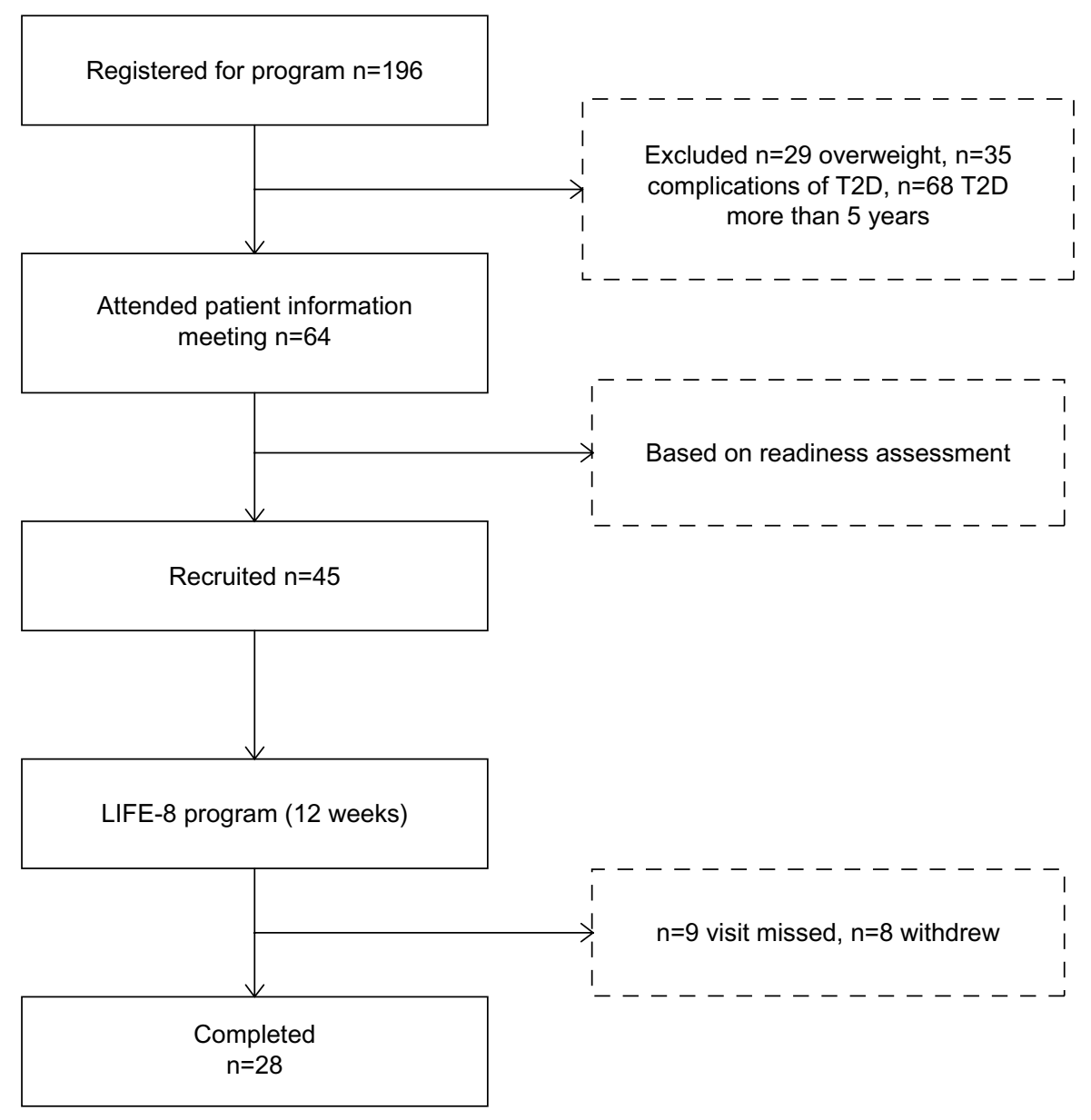

Figure I Flowchart of the program from screening to completion of LIFE-8.

Abbreviations: T2D, type 2 diabetes mellitus; yrs, years; LIFE-8, Lifestyle Intervention for Weight Loss-8. 


\section{Dietary intervention}

The initial assessment session included dietary recall (usual dietary recall), semistructured food frequency questionnaire, identification of individualized goals, and the handing over of the instructional material (diet plan, goal chart, food log, program schedule) developed by the registered dietitian. The suggested diet plan $(1,200-1,500 \mathrm{cal} / \mathrm{d})$ consisted of a combination of conventional balanced diet options as suggested by ADA guidelines and meal replacement as individualized by the dietitian. Two of the three main meals were replaced with a commercial meal replacement (Glucerna SR; Abbott Laboratories, Abbott Park, IL, USA) for 6 weeks, which contributed to $500 \mathrm{cal} / \mathrm{d}$, followed by one meal replacement of $250 \mathrm{cal} / \mathrm{d}$ for the following 6 weeks. Participants were advised on an equal calorie meal if they found the meal replacements unpalatable.

Another essential component of the program was group sessions conducted by a registered dietitian. The participants were provided with instructions on healthy eating and diet planning. They were educated on food groups, sources of carbohydrate, portion sizes, cereal exchanges, vegetable portions, ideal plate model, improvisation of local recipes, food labels, and conscious eating. ${ }^{15}$ Hands-on interactive learning during the healthy cooking sessions was offered by dietitians, which facilitated the learning process by allowing group interaction, engaging discussion, sharing cooking experiences, and the development of improvised healthy local recipes (Table 1).

\section{Physical activity intervention}

Improving physical activity was a strong focus of the program. All the participants were provided with a pedometer as a mobile tool and could be tracked online by the participant/ counselor. A physical therapist provided a structured exercise session twice a week (45 minutes) focusing on aerobic exercises, strength training, and stretching exercises. Participants were encouraged to incorporate moderate-intensity physical activity between 150 minutes/wk and 250 minutes/wk or a step count of 7,000-10,000 per day. ${ }^{16}$ However, the recommendations were individualized based on the physical fitness and medical condition of the participant.

\section{Behavioral modification intervention}

Behavioral therapy helps the participants to make long term, sustainable changes in their eating pattern, physical activity, and control the environmental cues that stimulate eating. ${ }^{17}$ Food diaries and pedometer activity records were advocated to inculcate the practice of self-monitoring. Additional emphasis was laid on recording the portions of cereals and vegetables. Educational sessions on the identification of appetite, hunger, and environmental cues for trigger eating were discussed as a stimulus control tool. The LIFE-8 program emphasized the need of specific, measurable, achievable, relevant, and time-bound (SMART) goals for weight loss, since goal setting has been reported to encourage the adoption of behavioral change and offer as a tool for self-evaluation. ${ }^{18}$ Motivational interviewing strategies of empathy, self-efficacy, and rolling with resistance were adapted during the counseling sessions (Table 1).

\section{Participant educational material}

Educational material was developed on the topics discussed during the sessions to support and reinforce the information. Diet diaries, goal charts, tips on the identification of environmental cues, physical activity, and healthy traditional recipes were made available for the participants.

\section{Outcome measures}

A pretested questionnaire was used to collect sociodemographic data, duration of diabetes, other medical conditions, and the history of weight loss. The outcomes were measured at 3 months on completion of the program. Nutritional knowledge was assessed by a pretested questionnaire before and after the program. Anthropometric measurements of height, weight, waist circumference, and body composition were taken with participants wearing light clothing and without shoes by the same person. Body weight and height were recorded using an electronic balance with stadiometer (SECA, Germany) to the nearest $0.1 \mathrm{~kg}$ and $0.1 \mathrm{~cm}$, respectively. Body composition was assessed by bioelectric impedance using an InBody-230 instrument (Biospace, Dogok-dong, South Korea) under standardized conditions. The BMI (calculated as weight $[\mathrm{kg}] /$ height $^{2}\left[\mathrm{~m}^{2}\right]$ ) was also estimated.

\section{Statistical analysis}

All the data were subjected to descriptive analysis, normal distribution was confirmed by histogram plots, and the data were presented as mean $\pm \mathrm{SD}$. Differences between preand postintervention data were assessed using paired $t$-test. Primary analysis was conducted similar to the intention to treat for all recruited participants as well as for program completers. Inferences for comparison were tested at the 5\% level of significance. All analyses were carried out with the Stata Statistical Software: Release 14 (StataCorp LP, College Station, TX, USA). 
Table 2 Demographic characteristics of participants at baseline

\begin{tabular}{|c|c|c|c|}
\hline Variable & $\begin{array}{l}\text { Total no of } \\
\text { participants }\end{array}$ & $\begin{array}{l}\text { Participants } \\
\text { with obesity }\end{array}$ & $\begin{array}{l}\text { Participants with obesity } \\
\text { and type } 2 \text { diabetes }\end{array}$ \\
\hline Recruited (n) & 45 & 28 & 17 \\
\hline Completed (n) & 28 & 19 & 9 \\
\hline Female (\%) & 100 & 100 & 100 \\
\hline Age (years), mean $\pm S D$ & $42 \pm 9$ & $40 \pm 9$ & $46 \pm 9$ \\
\hline Weight $(\mathrm{kg})$, mean $\pm \mathrm{SD}$ & $98.2 \pm 19.4$ & $97.0 \pm 19.1$ & $100.6 \pm 20.9$ \\
\hline Body mass index $\left(\mathrm{kg} / \mathrm{m}^{2}\right)$, mean $\pm \mathrm{SD}$ & $40.4 \pm 7.4$ & $39.9 \pm 6.8$ & $41.4 \pm 9$ \\
\hline \multicolumn{4}{|c|}{ Educational attainment (\% participant) } \\
\hline Elementary school & 16 & 7 & 33 \\
\hline High school & 63 & 66 & 56 \\
\hline Bachelor's degree & 21 & 27 & 11 \\
\hline \multicolumn{4}{|c|}{ Reason to lose weight (\% participant) } \\
\hline Aesthetic purpose & 8 & 13 & 0 \\
\hline Improve health & 54 & 40 & 78 \\
\hline Improve quality of life & 38 & 47 & 22 \\
\hline \multicolumn{4}{|c|}{ Tried to lose weight before (\% participant) } \\
\hline Yes & 96 & 100 & 100 \\
\hline No & 4 & 0 & 0 \\
\hline
\end{tabular}

Abbreviation: SD, standard deviation.

\section{Results}

Screening of participants, enrollment, and the followup sequence are shown in Figure 1, while the baseline characteristics are described in Table 2. The participants were divided based on obesity versus obesity with T2D, and no significant difference was recorded between these subgroups at baseline. Eighty-four percent of participants were reasonably educated, and the purpose of seeking the weight loss program was largely to improve health and the quality of life in both subgroups. Ninety-eight percent of total participants tried to lose weight through dietary restriction and exercises, with no success in weight maintenance.

Table 3 presents the changes in measures of body weight, fat mass, FBG, and HbA1c during the LIFE-8 program. On analyzing the data for completers $(n=28)$, we found a significant $(P<0.01)$ weight loss of $4.8 \pm 2.8 \mathrm{~kg}$ (5.0\%) (95\% CI 3.7-5.8), fat loss 3.8 $\pm 3.0 \mathrm{~kg}(7.8 \%)(95 \%$ CI 2.6-5.1), and reduction in waist circumference $4 \pm 4 \mathrm{~cm}$ (95\% CI 1.8-5.6) after the 3-month program. On comparing the two subgroups, we observed that both showed a significant $(P<0.01)$ reduction in body weight, BMI, and fat mass. A significant improvement $(P<0.01)$ in glycemic control (HbA1c and FBG) was observed in participants with obesity and T2D.

After 1-year follow-up of the completers $(n=28)$, we found that they could maintain $4.0 \%$ weight loss $(<0.001)$ compared to baseline (Figure 2). Participants with type 2 diabetes $(n=9)$ showed a sustained glycemic control after 12 months with FBG (Table 4).

\section{Participant feedback}

Since evaluation and feedback are the key to learn and improve, all the participants were encouraged to fill a standardized knowledge questionnaire before and after the program, the purpose of which was to study the changes in the nutritional knowledge, ie, self-monitoring, portion control, appetite control, common mistakes occurring during dietary intervention, food exchanges, ideal plate, food labeling, healthy cooking, and myths about weight loss. The average score had increased from $4 / 10$ to $7 / 10$ after the program $(P<0.01)$. The sessions on weight maintenance, healthy cooking, and food labeling scored the highest. Visual analog scale ranging from 0 to 10 measured the overall acceptance of the program and was observed as $9 / 10$. The cost of the program to the clinic was $\sim$ US $\$ 160$ per participant. However, this excluded the cost of meal replacements and the pedometer.

\section{Discussion}

These results indicate that the LIFE-8 program was successful in translating evidence-based guidelines for weight management in clinical practice in the UAE. The outcome of this program encourages us to appreciate its benefits not only for contributing to weight loss and fat loss but also in improving the glycemic control inT2D participants.

This program was offered to participants with obesity and T2D after a thorough screening process based on the inclusion-exclusion criteria and readiness assessment. As reported earlier, assessing the readiness to change not only 
Table 3 Effect of LIFE-8 program on anthropometric parameters and glycemic control in completers

\begin{tabular}{|c|c|c|c|c|c|c|}
\hline \multirow[t]{2}{*}{ Variable } & \multicolumn{2}{|c|}{ Total no of participants } & \multicolumn{2}{|c|}{ Participants with obesity } & \multicolumn{2}{|c|}{$\begin{array}{l}\text { Participants with obesity } \\
\text { and T2D }\end{array}$} \\
\hline & Before & After & Before & After & Before & After \\
\hline Weight $(\mathrm{kg})$ & $98.2 \pm 19.4$ & $93.4 \pm 19.4 *$ & $97.0 \pm 19.1$ & $91.9 \pm 19.2^{*}$ & $100.6 \pm 20.9$ & $96.7 \pm 20.5^{*}$ \\
\hline Body mass index $\left(\mathrm{kg} / \mathrm{m}^{2}\right)$ & $40.4 \pm 7.4$ & $38.4 \pm 7.4^{*}$ & $39.9 \pm 6.8$ & $37.7 \pm 6.9 *$ & $41.4 \pm 9.0$ & $39.8 \pm 8.6 *$ \\
\hline Fat mass $(\mathrm{kg})$ & $48.5 \pm 13.0$ & $44.7 \pm 13.9^{*}$ & $47.4 \pm 12.6$ & $43.8 \pm 13.1 *$ & $50.5 \pm 14.1$ & $46.3 \pm 15.8 *$ \\
\hline Muscle mass (kg) & $13.0 \pm 2.1$ & $13.0 \pm 2.1$ & $13 \pm 2.2$ & $12.7 \pm 2.0$ & $13.2 \pm 2.1$ & $13.8 \pm 2.3$ \\
\hline Water mass (kg) & $36.4 \pm 6.1$ & $36.0 \pm 6.0$ & $36.2 \pm 6.6$ & $34.9 \pm 5.9$ & $36.9 \pm 6.3$ & $37.8 \pm 6.3$ \\
\hline Waist circumference $(\mathrm{cm})$ & $110 \pm 14$ & $106 \pm 14 *$ & $103 \pm 11$ & $99 \pm 11 * *$ & $116 \pm 15$ & $112 \pm 15^{* *}$ \\
\hline Fasting blood glucose $(\mathrm{mmol} / \mathrm{L})$ & - & - & $5.5 \pm 0.7$ & $5.3 \pm 0.6$ & $8.2 \pm 2.0$ & $6.8 \pm 0.8 * *$ \\
\hline $\mathrm{HbAlc}(\%)$ & - & - & $5.6 \pm 0.3$ & $5.5 \pm 0.3$ & $7.1 \pm 1.0$ & $6.6 \pm 0.7 * *$ \\
\hline
\end{tabular}

Notes: $* P<0.01$. $* * P<0.05$. Data presented as mean $\pm S D$.

Abbreviations: LIFE-8, Lifestyle Intervention for Weight Loss; T2D, type 2 diabetes; HbAlc, hemoglobin AIc; SD, standard deviation.

adds an extra step in facilitating the weight loss process but also indicates patient compliance. ${ }^{19-21}$ Although the program was developed and open for registration for both sex, very few male participants were registered, inadequate to form a group of 6-8. We observed that women seemed to more enthusiastic about participation unlike men, which could be due to the time demanded for this program, as it was offered during morning time on working days. Men were unable to confirm their attendance to the educational sessions at the clinic. The participants were divided into homogenous groups based on their age, educational level, and medical condition. The educational material and the teaching techniques varied marginally based on the conception of the participants in each group. The LIFE- 8 program could deliver an average weight loss of $4.8 \pm 2.8$ (5.0\%) (program completers, $\mathrm{n}=28$ ) and 3.2 \pm 2.8 $(3.2 \%)$ (recruited, $\mathrm{n}=45$ ). This weight loss was comparable to the average weight loss reported in the systematic review and meta-analysis of 28 studies applying the findings of the Diabetes Prevention Program across diverse settings and population, which showed a $4 \%-5 \%$ weight loss that was maintained for a follow-up period of 9 months. ${ }^{22}$ The weight loss was reflective of decreased $(P<0.01)$ fat mass and waist circumference in the participants $(7.8 \%$ and $3.7 \%)$. These observations are in consonance with the results of a meta-analysis of 56 studies in class II and III obese individuals showing that lifestyle interventions incorporating physical activity improved not only weight loss but also various cardiometabolic risk factors. ${ }^{23}$ A significant improvement in the glycemic control was not only observed in the subgroup of participants with obesity and T2D (Table 4) but also in a small subgroup $(n=6)$ with obesity and prediabetes, showing a substantial improvement $(P=0.04)$ in $\mathrm{HbAl}$ c after the 3 -month program (5.8\% vs $5.5 \%$ ). This could be attributed to clinically relevant health benefits of weight loss on glucose metabolism. ${ }^{24}$

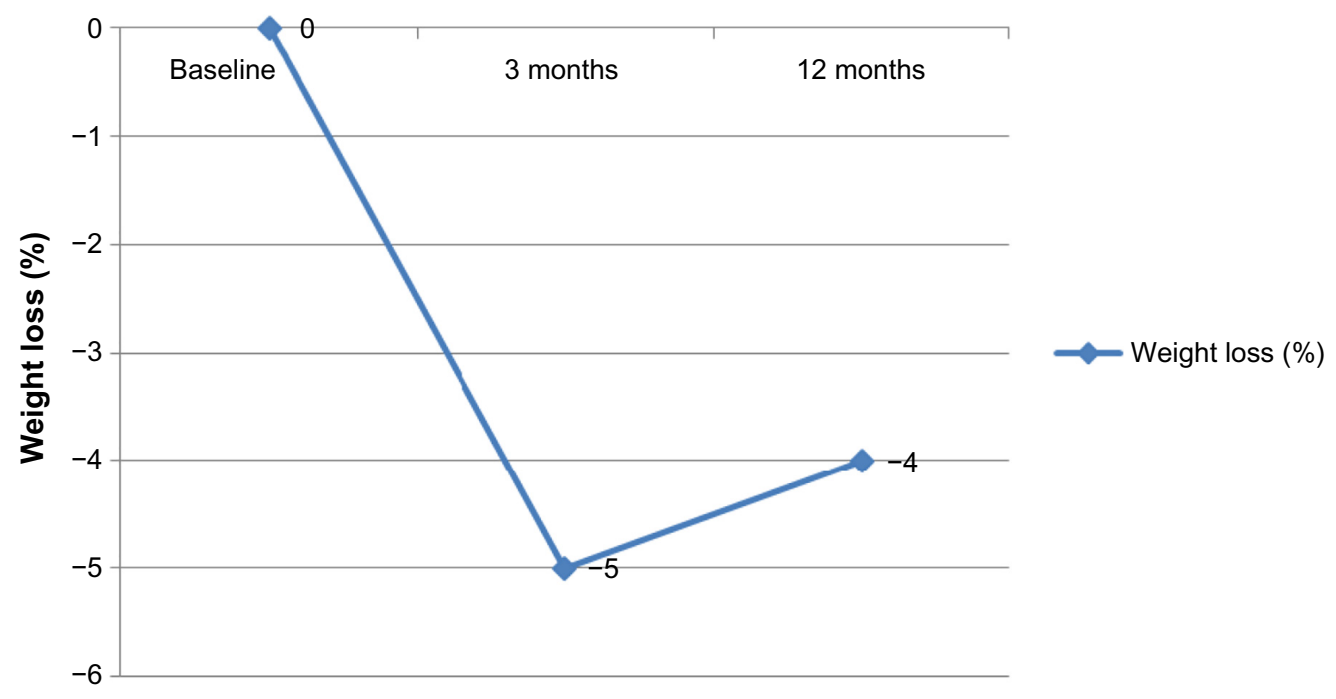

Figure 2 Changes in body weight percentage during I-year follow-up of the completed participants. 
Table 4 Effect of LIFE-8 on the glycemic control of type 2 diabetic participants $(n=9)$

\begin{tabular}{llll}
\hline Variable & $\begin{array}{l}\text { Before } \\
\text { intervention }\end{array}$ & $\begin{array}{l}\text { After } \\
\text { intervention }\end{array}$ & $\begin{array}{l}\text { I2-month } \\
\text { follow-up }\end{array}$ \\
\hline $\begin{array}{l}\text { Fasting blood glucose } \\
\text { (mmol/L) }\end{array}$ & $8.2 \pm 2.0$ & $6.8 \pm 0.8^{\mathrm{a}}$ & $6.6 \pm 1.4^{\mathrm{a}}$ \\
$\mathrm{HbAlc}(\%)$ & $7.1 \pm 1.0$ & $6.6 \pm 0.7^{\mathrm{a}}$ & $6.3 \pm 0.7^{\mathrm{a}}$ \\
\hline
\end{tabular}

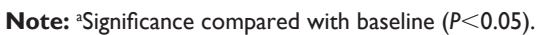

Abbreviations: LIFE-8, Lifestyle Intervention for Weight Loss; HbAIc, hemoglobin Alc.

This program could deliver equally effective results in eight sessions compared to programs offering more than eight sessions ( $4 \%)$ as described in a meta-analysis. ${ }^{22}$ Although a few studies have reported that the magnitude of weight loss is related to the number and frequency of sessions, ${ }^{25,26}$ some have shown that programs of longer duration result in a higher dropout rate. ${ }^{27}$ Although we could not refer to similar programs in the Emirates, a 12-month intensive intervention in Arab women in this region has reported a decrease of $2.4 \pm 0.4 \mathrm{~kg}$ body weight, which is comparable to the results of this program. ${ }^{28}$ One of the major reasons for not having "translated" lifestyle intervention programs into routine clinical practice is the cost incurred. Nevertheless, this program could be adapted in other clinical settings with a reasonable budget. With increased emphasis on the behavioral modification throughout this program, we observed changes in participant perception and attitude toward eating behavior and physical activity.

\section{One-year follow-up}

A significant change $(P<0.01)$ in body weight was observed after 1 year compared to baseline $(\sim 4 \%)$. This result was comparable to the meta-analysis of 22 translational studies where the intervention arms showed a weight loss of $2.3 \mathrm{~kg}$ in 12 months. ${ }^{29}$ Emiratis women participating in LIFE-8 could maintain their weight loss for 1 year, probably in part because they were more familiar, competent, and comfortable with the know-how of weight management and were able to practice it in grocery purchase, food preparation, meal portioning, increasing physical activity, and recognition of cues for overeating. We believe that these changes improve the possibility of lasting weight loss. While the program delivered a modest weight loss, it could not continue further weight loss after the cessation of the intensive program.

A subgroup analysis of glycemic control in T2D participants $(\mathrm{n}=9)$ showed a significant improvement $(P<0.05)$ in fasting plasma glucose $(8.2 \pm 2.0 \mathrm{mmol} / \mathrm{L}$ vs $6.6 \pm 0.8 \mathrm{mmol} / \mathrm{L})$ and $\mathrm{HbA} 1 \mathrm{c}(7.1 \% \pm 1.0 \%$ vs $6.3 \% \pm 0.7 \%)$ even after 1 year of the program. Haimoto et al have reported a significant improvement in $\mathrm{HbA} 1 \mathrm{c}$ after 2 years in patients with $\mathrm{T} 2 \mathrm{D}$ on loose restriction of carbohydrate intake compared to conventional diet. However, whether the improvement in glycemic control is a result of weight loss or changes in total energy and nutrient intake is still being investigated. ${ }^{30}$ The National Health Interview Survey studied 1,401 overweight diabetic patients and reported that individuals trying to lose weight had $23 \%$ lower mortality rate than others, suggesting that eating less may have a beneficial effect in the long term even if weight loss is not achieved. ${ }^{31}$

The strength of this study is that this is one of the first evaluations of a lifestyle intervention program for obese and diabetic participants in this region. The program was developed based on available evidence and comprehensive clinical experience with the local Emirati community. However, the limitations to this study are the small sample size and its nonrandomized, pragmatic service assessment. The program has not been systematically compared with a control intervention program, and the sample included only women. Further evidence is required from a randomized, controlled trial to evaluate the short-term and long-term clinical advantages and cost-effectiveness of the LIFE-8 program in this region. Since this is an ongoing program, further studies with a larger sample size could increase the generalizability of the program.

\section{Conclusion}

With a high prevalence of obesity and diabetes in the UAE, an effective, affordable, acceptable, and adaptable lifestyle intervention program could add to the efforts essential for the prevention and management of diabetes. The LIFE- 8 program was successful in not only delivering a modest weight loss but also inducing improvement in glycemic control in diabetic participants. In addition, participants also maintained their body weight after a 12-month followup. However, there is a need for further analysis on a larger number of participants and execute the program in other health care facilities.

\section{Acknowledgments}

The authors would like to thank the participants and clinical staff for their support and cooperation. This program was supported by grants from the Rashid Center for Diabetes and Research and the Global Health Partner (Gothenburg, Sweden).

\section{Disclosure}

The authors report no conflicts of interest in this work. 


\section{References}

1. Malik M, Bakir A, Saab BA, King H. Glucose intolerance and associated factors in the multi-ethnic population of the United Arab Emirates: results of a national survey. Diabetes Res Clin Pract. 2005;69:188-195.

2. Hajat C, Harrison O, Shather Z. A profile and approach to chronic disease in Abu Dhabi. Global Health. 2012;8:18.

3. Kelley DE. Managing obesity as first-line therapy for diabetes mellitus. Nutr Clin Care. 1998;1:38-43.

4. Virtanen KA, Iozzo P, Hällsten K, et al. Increased fat mass compensates for insulin resistance in abdominal obesity and type 2 diabetes: a positron-emitting tomography study. Diabetes. 2005;54(9):2720-2726.

5. Maggio CA, Pi-Sunyer FX. The prevention and treatment of obesity. Application to type 2 diabetes. Diabetes Care. 1997;20(11): 1744-1766.

6. Van Gaal LF, Mertens IL, Ballaux D. What is the relationship between risk factor reduction and degree of weight loss? Eur Heart J Suppl. 2005;7(suppl L):L21-L26.

7. Knowler WC, Barrett-Connor E, Fowler SE, et al; Diabetes Prevention Program Research Group. Reduction in the incidence of type 2 diabetes with lifestyle intervention or metformin. $N$ Engl J Med. 2002;346(6):393-403.

8. Evidence Analysis Library [webpage on the Internet]. Adult Weight Management Evidence-Based Nutrition Practice Guideline, Evidence Analysis Library, Academy of Nutrition and Dietetics; ADA Evidence Analysis Library. Available from: http://andevidencelibrary.com/topic. cfm?format_tables=0\&cat=3014\&auth=1. Accessed March 21, 2013.

9. Unick JL, Beavers D, Jakicic JM, et al; Look AHEAD Research Group. Effectiveness of lifestyle interventions for individuals with severe obesity and type 2 diabetes: results from the Look AHEAD trial. Diabetes Care. 2011;34(10):2152-2157.

10. Paulweber B, Valensi P, Lindström J, et al. A European evidence-based guideline for the prevention of type 2 diabetes. Horm Metab Res. 2010;42(Suppl 1):S3-S36.

11. Neiberg RH, Wing RR, Bray GA, et al; Look AHEAD Research Group. Patterns of weight change associated with long-term weight change and cardiovascular disease risk factors in the Look AHEAD Study. Obesity (Silver Spring). 2012;20(10):2048-2056.

12. Ali HI, Bernsen RM, Baynouna LM. Barriers to weight management among Emirati women: a qualitative investigation of health professionals' perspectives. Int $Q$ Community Health Educ. 2008-2009; 29(2):143-159.

13. Kahan D. Prevalence and correlates of adult overweight in the Muslim world: analysis of 46 countries. Clin Obes. 2015;5(2):87-98.

14. LSU Hospitals [webpage on the Internet]. Assessing Patient Readiness for Change and Making Treatment Options. Available from: http://www. 1suhospitals.org/cmo/hcet/docs/obesityclinical/Patient_Readiness.pdf. Accessed January 27, 2016.

15. Evert AB, Boucher JL, Cypress M, et al. Nutrition therapy recommendations for the management of adults with diabetes. Diabetes Care. 2014;37(Suppl 1):S120-S143.

16. Donnelly JE, Blair SN, Jakicic JM, et al; American College of Sports Medicine. American College of Sports Medicine Position Stand. Appropriate physical activity intervention strategies for weight loss and prevention of weight regain for adults. Med Sci Sports Exerc. 2009;41(2):459-471. doi: 10.1249/MSS.0b013e3181949333. [Erratum in: Med Sci Sports Exerc. 2009;41(7):1532].
17. Bray GA [webpage on the Internet]. Obesity in adults: behavioral therapy. Available from http://www.uptodate.com/contents/obesity-inadults-behavioral-therapy?source=search_result\&search=obesity+in+ adults+behavioral+therapy\&selectedTitle $=1 \sim 150$. Accessed January 27, 2016.

18. Cullen KW, Baranowski T, Smith SP. Using goal setting as a strategy for dietary behavior change. J Am Diet Assoc. 2001;101(5):562-566.

19. Rao G, Burke LE, Spring BJ, et al; American Heart Association Obesity Committee of the Council on Nutrition, Physical Activity and Metabolism; Council on Clinical Cardiology; Council on Cardiovascular Nursing; Council on the Kidney in Cardiovascular Disease; Stroke Council. New and emerging weight management strategies for busy ambulatory settings: a scientific statement from the American Heart Association endorsed by the Society of Behavioral Medicine. Circulation. 2011;124(10):1182-1203.

20. Simkin-Silverman LR, Gleason KA, King WC, et al. Predictors of weight control advice in primary care practices: patient health and psychosocial characteristics. Prev Med. 2005;40(1):71-82.

21. Ward SH, Gray AM, Paranjape A. African Americans' perceptions of physician attempts to address obesity in the primary care setting. $J$ Gen Intern Med. 2009;24(5):579-584.

22. Ali MK, Echouffo-Tcheugui J, Williamson DF. How effective were lifestyle interventions in real-world settings that were modeled on the Diabetes Prevention Program? Health Aff (Millwood). 2012;31(1): 67-75.

23. Baillot A, Romain AJ, Boisvert-Vigneault K, et al. Effects of lifestyle interventions that include a physical activity component in class II and III obese individuals: a systematic review and meta-analysis. PLoS One. 2015;10(4):e0119017.

24. Aucott LS. Influences of weight loss on long-term diabetes outcomes. Proc Nutr Soc. 2008;67(1):54-59.

25. Kramer MK, Kriska AM, Venditti EM, et al. Translating the Diabetes Prevention Program: a comprehensive model for prevention training and program delivery. Am J Prev Med. 2009;37(6):505-511.

26. Graffagnino CL, Falko JM, La Londe M, et al. Effect of a communitybased weight management program on weight loss and cardiovascular disease risk factors. Obesity (Silver Spring). 2006;14(2):280-288.

27. Pekarik G. The effects of program duration on continuance in a behavioral weight loss program. Addict Behav. 1987;12(4):381-384.

28. Kalter-Leibovici O, Younis-Zeidan N, Atamna A, et al. Lifestyle intervention in obese Arab women: a randomized controlled trial. Arch Intern Med. 2010;170(11):970-976.

29. Dunkley AJ, Bodicoat DH, Greaves CJ, et al. Diabetes prevention in the real world: effectiveness of pragmatic lifestyle interventions for the prevention of type 2 diabetes and of the impact of adherence to guideline recommendations: a systematic review and meta-analysis. Diabetes Care. 2014;37(4):922-933. doi: 10.2337/dc13-2195. [Review. Erratum in: Diabetes Care. 2014;37(6):1775-1776].

30. Haimoto H, Iwata M, Wakai K, Umegaki H. Long-term effects of a diet loosely restricting carbohydrates on $\mathrm{HbA1c}$ levels, BMI and tapering of sulfonylureas in type 2 diabetes: a 2-year follow-up study. Diabetes Res Clin Pract. 2008;79(2):350-356.

31. Gregg EW, Gerzoff RB, Thompson TJ, Williamson DF. Trying to lose weight, losing weight, and 9-year mortality in overweight U.S. adults with diabetes. Diabetes Care. 2004;27(3):657-662.

Diabetes, Metabolic Syndrome and Obesity: Targets and Therapy

\section{Publish your work in this journal}

Diabetes, Metabolic Syndrome and Obesity: Targets and Therapy is an international, peer-reviewed open-access journal committed to the rapid publication of the latest laboratory and clinical findings in the fields of diabetes, metabolic syndrome and obesity research. Original research, review, case reports, hypothesis formation, expert opinion and commentaries are all considered for publication. The manuscript management system is completely online and includes a very quick and fair peer-review system, which is all easy to use. Visit http://www.dovepress.com/testimonials.php to read real quotes from published authors. 